\title{
ESTÁGIO CURRICULAR: SISTEMATIZAÇÃO E PERCEPÇÃO DOS SUJEITOS ENVOLVIDOS
}

\author{
CURRICULAR INTERNSHIP: SYSTEMATIZATION AND \\ PERCEPTION OF THE SUBJECTS INVOLVED \\ PRÁCTICACURRICULAR: SISTEMATIZACIÓN Y PERCEPCIÓN \\ DE LOS SUJETOS INVOLUCIONADOS
}

\begin{abstract}
Mari Clair Moro Nascimento ${ }^{\mathrm{I}}$
RAQUEL LAZZARI LEITE BARBOSA ${ }^{\mathrm{I}}$

I'Universidade Estadual Paulista "Júlio de Mesquita Filho" (UNESP), Marília/SP, Brasil
\end{abstract}

Resumo Para atingir o objetivo deste trabalho, mapear as implicações do estágio curricular na formação e na atuação para a docência, foi necessário o embasamento na pesquisa qualitativa, visto que ela analisa o objeto de estudo em toda sua complexidade. Tem-se, assim, como lócus de pesquisa, o estágio curricular, nos Anos Iniciais do Ensino Fundamental, estruturado em um curso de Pedagogia que acontece em uma universidade pública situada no norte do estado do Paraná. As informações obtidas foram coletadas por meio de observações, entrevista, questionário e pesquisa documental. A partir do objetivo proposto, buscou-se verificar como este estágio é concebido nos documentos institucionais e, ainda, como ele se efetiva em seu dia a dia. No entrelaçar do que consta nos documentos consultados e do que fora visto em seu cotidiano, são apresentadas ações, consideradas como positivas ou negativas pelos sujeitos participantes do estudo, que interferiram na formação docente ou nas escolas onde o estágio se concretizou. A partir dos dados apresentados ao longo do texto, nas considerações finais chama-se a comunidade acadêmica, especialmente a universidade, responsável pelo estágio curricular, no momento da formação inicial, a repensar sobre o que ainda precisa ser revisto em sua configuração e estruturação no intuito dar voz aos sujeitos da escola e formar o professor.

Palavras-chave: Cotidiano da escola; Estágio curricular; Formação inicial.

ABSTRact In order to achieve the objective of the study, to map the implications of the curricular internship in training and acting for teaching, it was necessary to base it on qualitative research, since it analyzes the object of study in all its complexity. Thus, the curricular internship, in the Early Years of Elementary Education, is organized as a locus of research, structured in a Pedagogy course that takes place in a public university located in the north of 
the state of Paraná. The information obtained was collected through observations, interviews, questionnaires and documentary research. Based on the proposed objective, we sought to verify how this internship is conceived in institutional documents and, also, how it is carried out in a daily life. In the interweaving of what appears in the consulted documents and what has been seen in the routines, actions are presented, considered as positive or negative by the subjects participating in the study, which interfered in the teacher training or in the schools where the internship took place. From the data presented throughout the text, in the final remarks the academic community, especially the university, which is responsible for the curricular internship, at the time of initial training, is called upon to rethink what still needs to be revised in its configuration and structuring, with a view to giving voice to school subjects and training teachers who know how to deal with the challenges of contemporary school.

KEYWORDS: SCHOOL DAILY LIFE; CURRICULAR INTERSHIP; INITIAL FORMATION.

RESUMEN Para lograr el objetivo del estudio, mapear las implicaciones de la práctica curricular en la formación y actuación para la docencia, se necesitó basamento en la investigación cualitativa, ya que en ello, se analiza el objeto de estudio en toda su complejidad. De esa manera, se tiene como locus de investigación, la práctica curricular en los Primeros Años de la Escuela Primaria, estructurado en un curso de Pedagogía que se lleva a cabo en una universidad pública ubicada en el norte de la provincia de Paraná. Las informaciones obtenidas se recopilaron a través de observaciones, entrevista, cuestionario e investigación documental. Basándonos en el objetivo propuesto, se buscó verificar cómo se concibe esta práctica en los documentos institucionales y también, cómo se efectiva a diario. En el entrelazamiento de lo que figura en los documentos consultados y de lo que se vió en el cotidiano, se presentan acciones, consideradas positivas o negativas por los sujetos participantes del estudio, que interfirieron en la formación del profesorado o en las escuelas donde tuvieron lugar las prácticas. A partir de los datos presentados a lo largo del texto, en las consideraciones finales se llama la comunidad académica, especialmente la universidad, responsable de las prácticas curriculares, en el momento de la formación inicial, para repensar lo que aún hay que revisar en su configuración y estructuración, con el fin de darles voz a los sujetos de la escuela y formar al profesor que sepa hacer frente a los retos de la escuela contemporánea.

Palabras Clave: Cotidiano de la escuela; Prática curricular; Formación inicial.

\section{INTRODUÇÃo}

Alicerçado na pesquisa qualitativa, este estudo ${ }^{1}$, a partir do estágio curricular nos Anos Iniciais do Ensino Fundamental desenvolvido em uma universidade pública ${ }^{2}$ situada no norte do estado do Paraná, objetiva "mapear as implicações do estágio curricular na for-

1 Este texto apresenta parte dos dados que constam em pesquisa de doutorado defendida no ano de 2018. Ressalta-se que o projeto de pesquisa foi submetido em 08/08/2014 ao Comitê de Ética em Pesquisa da Universidade Estadual Paulista Júlio de Mesquita - Campus de Marilia, sendo aprovado e homologado na Reunião do CEP da FFC da UNESP em 22/10/2014 no Parecer do Projeto no 1099/2014

2 Para a realização da pesquisa na referida universidade, foi apresentado no dia 08/08/2014, à Vice-Chefe do Departamento de Educação o projeto do estudo, a Folha de Rosto para Pesquisa Envolvendo Seres Humanos e um outro documentos com informações sobre a pesquisa, quando houve autorização, mediante assinatura da representante do Departamento de Educação, para a realização deste estudo. 
mação e na atuação para a docência". Por adentrar no campo social em que se efetivam as ações dos professores, os dados foram coletados em três escolas em que o estágio curricular foi realizado no ano de 2016, a fim de estar em contato com os sujeitos envolvidos no processo: coordenadora e supervisoras de estágio da universidade, estagiários, alunas egressas da instituição pesquisada, diretoras, pedagogas e professoras regentes das escolas. Utilizou-se, para o levantamento das informações, documentos institucionais da universidade pesquisada, por possibilitarem o conhecimento de como é a proposta para desenvolvimento do estágio curricular. Houve, também, leitura e análise das Propostas Pedagógicas das instituições em que o estágio aconteceu para saber quais princípios orientam a formação do aluno em cada uma delas. Além da consulta em documentos institucionais, outros dados foram adquiridos por meio de observação, questionário e entrevista.

O texto apresenta o percurso metodológico, as finalidades do estágio curricular, segundo alguns estudiosos da temática, a sistematização do estágio curricular na instituição pesquisada, apontamentos sobre a percepção dos sujeitos envolvidos no estágio curricular e as considerações finais.

\section{Percurso metodológico}

Para compreender como se configura o objeto de estudo, na instituição pesquisada, foi utilizada a abordagem qualitativa, por favorecer a compreensão de toda a complexidade que o envolve, pois "[...] esta metodologia observa, no mesmo movimento, o sujeito e a sociedade em interacção, mas também, e simultaneamente, os factos e as emoções que os acompanham" (GUERRA, 2008, p. 19). Para isso, foi necessária atenção às características anunciadas por Bogdan e Biklen (1994): (a) apreender a perspectiva dos participantes; (b) estudar o fenômeno no seu ambiente natural; (c) apresentar os dados, na sua maioria, de forma descritiva; (d) atentar muito mais para o processo do que para o produto e (e) analisar os dados de forma indutiva, visto que o olhar para tais aspectos oportunizou apreender e conhecer o cotidiano do estágio curricular na universidade pesquisada, pois "Um dos desafios atualmente lançados à pesquisa educacional é exatamente o de tentar captar essa realidade dinâmica e complexa do seu objeto de estudo, em sua realização histórica" (LÜDKE; ANDRÉ, 1986, p. 5), porque existem “[...] inúmeras variáveis agindo e interagindo ao mesmo tempo" (LÜDKE; ANDRÉ, 1986, p. 4).

Desvendar o estágio curricular demandou estar no contato direto com os sujeitos participantes por meio dos procedimentos de coleta de dados: observações, questionários, entrevista e análise documental nos Projetos Político-Pedagógicos do curso de Pedagogia (UNIVERSIDADE ESTADUAL, 2005, 2007, 2010) da universidade pesquisada para conhecer como é indicada a sua configuração. Foram retiradas também informações das Propostas Político-pedagógicas (LONDRINA, 2015, 2016, 2017) das $\operatorname{escolas}^{3}$ em que o estágio curricular se concretizou, tendo em vista conhecê-las em sua estrutura, em seu aten-

\footnotetext{
3 As escolas participantes do estudo foram aquelas que estavam sob a responsabilidade das supervisoras que tinham a atividade do estágio curricular. Essas foram as docentes da Área dos Anos Iniciais do Ensino Fundamental, da universidade pesquisada, convidadas a serem também sujeitos da pesquisa, por serem concursadas. O fato é que, entre os demais professores da referi da área, uns estavam sem essa atividade ou ainda, o estágio curricular estava sob a responsabilidade dos diversos Professores Colaboradores, aqueles que podem ter seus contratos encerrados a qualquer momento, o que interferiria na dinâmica do estágio, caso essa substituição se desse no decorrer do processo analisado.
} 
dimento e em seus pressupostos teóricos.

A análise dos dados coletados aconteceu no entrelaçar do corpus teórico delimitado no estudo com o que fora revelado pelos sujeitos participantes, por ser importante levar em consideração o que ocorre em seu dia a dia e os apontamentos teóricos daqueles que já se aproximaram deste objeto de estudo, ou seja, o que revelam outros pesquisadores sobre a temática, pois "O esforço compreensivo tem o sentido de valorizar ao máximo os achados do campo" (MINAYO, 2012, p. 624).

Participaram da pesquisa 33 sujeitos ${ }^{4}$ identificados por siglas: a coordenadora do estágio curricular (CE), também participante neste estudo na função de supervisora; três supervisoras de estágio curricular da instituição pesquisada (S1; S2; S3); nove estagiários que estavam sob a supervisão delas (E1; E2; E3; E4; E5; E6; E7; E8; E9); seis professoras regentes (PR1; PR2; PR3; PR4; PR5; PR6), atuantes, na escola, na função de orientadoras junto aos estagiários; três pedagogas (P1, P2, P3); duas diretoras (D1, D2) e dez alunas egressas da instituição pesquisada (AE1; AE2; AE3; AE4; AE5; AE6; AE7; AE8; AE9; AE10), as quais já são professoras nos Anos Iniciais do Ensino Fundamental. As três escolas participantes estão nomeadas por ESC1, ESC2 e ESC3. No desenvolvimento do texto, a sigla de cada sujeito acompanhada por S1, S2 ou S3, após o traço, é para indicar com qual supervisora de estágio houve o contato, por ser essencial saber de que lugar cada participante se pronuncia, como por exemplo: E5-S3 (estagiário cinco esteve sob a orientação da supervisora três); ESC2-S2 (na escola dois foi concretizado o estágio com a supervisora dois). O pronunciamento de alguns dos sujeitos envolvidos na pesquisa está destacado ao longo do texto em itálico.

Finalidades do estágio curricular: fundamentos teóricos

O estágio curricular obrigatório para formar ao exercício da docência efetiva-se na instituição escolar por ser o campo social em que os futuros professores desenvolverão suas atividades profissionais, quando da conclusão da formação inicial (PIMENTA, 2011), sendo indicado por Giglio et al. (2011, p. 24) que

As escolas, em especial as pertencentes às redes públicas de ensino, são campos

4 Os sujeitos envolvidos no estudo são aqueles que estavam no contexto e que aceitaram participar. Acerca da participação das supervisoras, já houve esclarecimentos. Sobre a participação dos estagiários, cabe esclarecer que cada supervisora tinha um número de estudantes sob sua responsabilidade, todos foram convidados a estarem na pesquisa, no entanto, tendo em vista o caráter qualitativo do estudo, que demandaria uma cuidadosa análise e atenção às vozes dos envolvidos, restringiu-se aos três primeiros estagiários que se manifestaram. Sobre o envolvimento dos sujeitos das escolas onde o estágio aconteceu, Diretoras, Pedagogas e Professoras Regentes, foram as pessoas que aceitaram participar do estudo, sendo convidadas todas as professoras de cada escola, mas houve a aceitação de três de cada uma delas. No que se refere às Diretoras, uma delas não devolveu o instrumento de coleta, motivo pelo qual há a participação de apenas duas. A participação das alunas egressas se deu mediante a busca por aquelas que estavam no exercício da docência nos Anos Iniciais do Ensino Fundamental em escolas públicas municipais e que tinham sido formadas a partir do currículo de 2007 ou de 2010. A Coordenadora do Estágio, membro do Colegiado de Pedagogia, foi inserida apenas após a qualificação do estudo, por sugestão da banca, para esclarecimento de alguns pontos que surgiram nas respostas dos estagiários. 
privilegiados de aprendizagem prática das instituições formadoras de professores em nível superior, por serem lugares característicos da diversidade e onde os saberes profissionais se desenvolvem.

O contato do estagiário com o seu futuro campo profissional, no instante do estágio curricular, não visa oferecer-lhe modelo de atividades a serem reproduzidas quando estiver no exercício da profissão, mas desencadear reflexões sobre como as práticas docentes têm sido instituídas no contexto da sala de aula, pois, segundo Oliveira-Formosinho (2007a, 2007b), existem professores que embasam suas ações na pedagogia transmissiva e outros na participativa, sendo importante a compreensão de seus fundamentos teóricos, porque cada uma delas imprime atuações diferenciadas dos professores junto aos alunos.

Na pedagogia transmissiva, a atuação docente acontece para comunicar os conhecimentos ao aluno, que os recebe passivamente, por meio da escuta ativa da fala do professor. Nessa forma de ensinar, são priorizadas atividades individuais e de memorização (OLIVEIRA-FORMOSINHO, 2007a, 2007b), pois a crença é de que a mente do aluno é uma tábula rasa a ser preenchida, configurando-se a prática pedagógica como o "[...] diálogo de um para outrem" (BRUNER, 1996, p. 85).

Todavia, na pedagogia participativa, o conhecimento ocorre por meio da interação ativa entre os sujeitos envolvidos no processo, sendo a escuta e o diálogo aspectos que embasam a ação docente, no intuito de formar pessoas que compreendam a realidade em que se inserem, para nela intervir quando pertinente (OLIVEIRA-FORMOSINHO, 2007a, 2007b). Nessa forma de efetivar a ação pedagógica, segundo Morgado (2012, p. 21),

[...] existe uma ponte entre a intencionalidade do educador e a participação da criança no ato de aprender e de experienciar. Neste sentido, o educador deve ser ativo e dinâmico, interessando-se pelas necessidades e interesses de cada criança, orientando-as e questionando-as de modo a promover experiências de aprendizagem de qualidade. A criança é, assim, entendida como um cidadão ativo e como ator e autor do seu conhecimento.

Assim efetivado o fazer pedagógico, ele acontece embasado no exercício da práxis, conceituada por Vázquez (1968) como uma atividade consciente que favorece o homem transformar a si mesmo e à natureza por meio de uma prática articulada a uma teoria, porque nessa perspectiva,

[...] entre a teoria e a atividade prática transformadora se insere um trabalho de educação das consciências, de organização dos meios materiais e planos concretos de ação; tudo isso como passagem indispensável para desenvolver ações reais, efetivas. Nesse sentido uma teoria é prática na medida em que materializa, através de uma série de mediações, o que antes só existia idealmente, como conhecimento da realidade ou antecipação ideal de sua transformação (VÁZQUEZ, 1968, p. 207).

Ainda sob a perspectiva de Vázquez (1968), o exercício da práxis promove a passagem da consciência ingênua para a filosófica, oportunizando que, a partir da aquisição da cultura, os sujeitos compreendam a sua realidade e busquem formas de modificá-la, ação 
esta que precisa estar presente na atuação docente (SACRISTÁN, 2005).

A atenção do estagiário para conhecer as práticas efetivadas pelos professores regentes, em especial, para a intencionalidade existente nas ações pedagógicas, demanda-lhe reconhecer a relação teoria e prática estabelecida na sala de aula dos Anos Iniciais do Ensino Fundamental, visto que elas não podem se dissociar, pois "A teoria pode contribuir para a transformação do mundo, mas para isso tem que sair de si mesmo e, em primeiro lugar, tem que ser assimilada pelos que vão ocasionar, com atos reais, efetivos, tal transformação" (VÁZQUEZ, 1968, p. 206). Diante do exposto, torna-se viável que o professor incorpore uma teoria que visa à transformação, se deseja atuar diferente da pedagogia transmissiva, porque "[...] uma prática será transformada à medida que exista uma elaboração teórica que justifique a necessidade de sua transformação e que proponha as formas da transformação [...]" (VÁZQUEZ, 1968, p. 107).

Com este olhar para o que acontece na escola e na sala de aula, o estagiário acaba por problematizar a realidade escolar e vai, pouco a pouco, identificando as teorias que embasam as concepções de quem está no cotidiano da escola e também percebendo as suas próprias, construindo, assim, a sua identidade docente, pois, de acordo com Piconez (1991, p. 27),

Com a prática da reflexão sobre a prática vivida e concebida teoricamente, são abertas perspectivas de futuro proporcionadas pela postura crítica, mais ampliada, que permitem perceber os problemas que permeiam as atividades e a fragilidade da prática.

Então, o contato do estagiário com professoras regentes, no dia a dia da escola, pode favorecer o futuro professor à revisão de suas próprias concepções pedagógicas, uma ação importante porque, caso elas não oportunizem melhorias nas aprendizagens dos educandos, ressignificá-las é relevante. Nesta perspectiva, cabe atentar para o que anunciam Silva e Gaspar (2018, p. 206), porque consta em seu estudo, intitulado "Estágio supervisionado: a relação teoria e prática reflexiva na formação de professores do curso de Licenciatura em Pedagogia" que

O estágio supervisionado é um espaço de aprendizagem da profissão docente e de construção da identidade profissional. Assim, ele é compreendido como campo de conhecimento e a ele deve ser atribuído um estatuto epistemológico indissociável da prática, concebendo-o como práxis, o que o define como uma atitude investigativa que envolve a reflexão e a intervenção em questões educacionais.

Então, fica evidente a pertinência do professor reflexivo, aquele que

[...] seja capaz de investigar os problemas que se colocam no cotidiano escolar, de mobilizar conhecimentos, recursos e procedimentos para a sua superação, de avaliar a adequação das suas escolhas e, finalmente, de reorientar a ação para intervenções mais qualificadas no processo de aprendizagem dos alunos (CAIMI, 2008, p. 95-96).

No entanto, a reflexão precisa decorrer em ações que oportunizem a modificação de 
práticas reconhecidas como inadequadas no contexto atual, pois, conforme expõe Libâneo (2004, p. 138),

A reflexão sobre a prática não resolve tudo, a experiência refletida não resolve tudo. São necessárias estratégias, procedimentos, modos de fazer, além de um sólido conhecimento teórico, que ajudam a melhor realizar o trabalho e melhorar a capacidade reflexiva sobre o que e como mudar.

A permanência dos futuros professores na escola, ainda no período de formação, ou seja, no momento do estágio curricular, oportuniza o conhecimento das leis que regem o funcionamento deste campo social (KINCHELOE, 1997) porque

Uma escola não é apenas um conjunto de professores. Uma escola é uma entidade social que não é mera reunião de indivíduos com diferentes papéis. Pode-se mesmo afirmar que cada escola desenvolve uma subcultura escolar própria à medida que passa o tempo e consolidam-se relações com a comunidade (AZANHA, 1998, p. 58).

Ou seja, cada escola tem a sua forma de funcionar porque o seu dia a dia se caracteriza a partir das concepções e formas de agir dos sujeitos que a compõem. Conforme anuncia Certeau (1998), o cotidiano da escola e da sala de aula se configura pelas artes ou maneiras de agir do homem ordinário, ator social e histórico que constituem aquela realidade. Assim, estar na escola, pode oportunizar, ao estagiário, a percepção sobre como a equipe escolar, especialmente os professores regentes, atuam para promover as aprendizagens dos alunos dos Anos Iniciais do Ensino Fundamental, ou melhor, como eles consolidam os produtos que lhes são indicados (CERTEAU, 1998), já que, segundo Farias (2002, p. 110), “[...] no interior da escola se fazem acordos, negociações e se estabelecem regras próprias que regulamentam tanto seu funcionamento burocrático, como as concepções, crenças e valores das pessoas que fazem seu coletivo". Portanto, envolvidos “[...] nessa realidade, os estudantes [estagiários] são convidados a agirem e pensarem (construírem práticas) pedagogicamente para que a docência adquira novas configurações, novas perspectivas e relações para o desenvolvimento e a realização humana" (ARAÚJO; MARTINS, 2020, p.195).

$\mathrm{O}$ olhar do estagiário, atento para o cotidiano escolar, possibilita compreender quais são as deficiências da escola contemporânea e ainda a identificar quais são os saberes necessários à atuação docente, aspectos indicados por Azanha (2004) como importantes na formação de professores, porque o exercício desta profissão demanda atentar para o contexto histórico em que se inserem os alunos, tornando-se "[...] um espaço de aprendizado crítico-reflexivo da profissão" (ARAÚJO; MARTINS, 2020, p. 195).

Nesta perspectiva, o estágio curricular supera a ideia limitada de ser considerado como a hora da prática, pois, de acordo com Lima e Aroeira (2011, p. 117), "O grande desafio do estágio é constituir-se como espaço de aprendizagem que nos leva a refazer continuamente a prática e a descobrir novos jeitos de compreender nosso fazer pedagógico [...]”.

Frente ao exposto, cabe atentar para o que indica Kincheloe (1997), que ressalta a relevância de formar o professor continuamente analítico frente às suas ações para ensinar, tendo em vista perceber as repercussões na formação do aluno, à escola e à sociedade, pois ensinar é um ato político que pode levar à manutenção ou à transformação de uma reali- 
dade (BOURDIEU; PASSERON, 1982). Conforme propõe Azanha (2004, p. 373), “[...] qualquer proposta de formação docente deve ter um sentido de investigação e de busca de novos caminhos". Para isso, as vivências no estágio curricular necessitam ser refletidas pelo estagiário, encorajando-o a ter uma consciência crítica que gere novos conhecimentos sobre como agir para oportunizar a aprendizagem dos sujeitos que compõem a escola contemporânea (KINCHELOE, 1997). Kincheloe (19997) ressalta, ainda, que os futuros professores voltem os olhares para perceber como os diferentes interesses da sociedade se manifestam na escola, especialmente, para compreender como os sujeitos, que estão no seu dia a dia, agem.

\section{A SiSTEMATIZAÇÃo do ESTÁGIO CURRICULAR NA UNIVERSIDADE PESQUISADA}

Para obter conhecimentos sobre o cotidiano do estágio curricular nos Anos Iniciais do Ensino Fundamental, na universidade pesquisada, foi preciso consultar os documentos institucionais (UNIVERSIDADE ESTADUAL, 2005, 2007, 2010), mas também estar em seu cotidiano, ou seja, em etapas que o constituem, entrelaçando o que fora indicado nos documentos e o que realmente foi efetivado. Nos documentos institucionais consultados, consta que este curso de Pedagogia prioriza a formação dos profissionais para a docência, sendo papel da universidade proporcionar a relação teoria e prática ao futuro professor. No que se refere ao estágio curricular, o curso visa propiciar a

\footnotetext{
Articulação entre os conhecimentos adquiridos durante o curso com a realidade profissional; utilização do referencial teórico do curso para análise das situações e planejamento das intervenções; elaboração, execução e avaliação dos projetos de intervenção (UNIVERSIDADE ESTADUAL, 2005, p. 60).
}

Nesta universidade, o estágio curricular é uma disciplina anual que “[...] constitui-se de atividades realizadas pelos estudantes com objetivo de propiciar vivências em situações reais de trabalho, envolvendo Supervisores de Estágio e Orientadores de Campo" (UNIVERSIDADE ESTADUAL, 2008, p. 01). Cabe esclarecer que é nomeado supervisor o professor da universidade que acompanha as atividades do estagiário e, de coordenador, o profissional que acompanha, na escola, as atividades dos estagiários, sendo geralmente um professor regente.

A sistematização deste estágio curricular está definida no documento Diretrizes do Estágio Curricular Obrigatório nos Anos Iniciais do Ensino Fundamental do Curso de Pedagogia (UNIVERSIDADE ESTADUAL, 2015), elaborado coletivamente pelos docentes da universidade responsáveis por ele. Nele, constam orientações sobre documentos que devem ser providenciados para a entrada do estagiário no campo, bem como outros utilizados ao longo do estágio e, ainda, as atividades que integram a carga horária anual de cem horas, divididas da seguinte forma: 1) Reuniões teóricas - 12 horas; (2) Análise da Proposta pedagógica do campo de estágio - 4 horas; (3) Observação participante - 21 horas; (4) Diário de campo - 5 horas; (5) Planejamento - 20 horas; (6) Intervenção - 20 horas; (7) Síntese reflexiva -7 horas e (8) Seminário de estágio - 4 horas. Das etapas apresentadas, foi possível estar, por meio da observação, nas reuniões teóricas, no primeiro dia da observação 
participante, em algumas intervenções e no seminário de estágio.

As observações tiveram início nas reuniões teóricas que aconteceram antes dos estagiários entrarem no campo e depois, quando já tinham algumas vivências, a partir das observações participantes, momento em que eles fizeram suas exposições acerca do que fora visto até então nas escolas e, coletivamente, estagiários e supervisoras refletiram sobre o que fora exposto, tendo em vista pensar sobre as práticas efetivadas e as concepções teóricas que as embasam. No instante das observações, foi possível ter contato com as leituras e reflexões realizadas sobre cada texto trabalhado pelas supervisoras, conforme quadro 1 :

Quadro 1 - Textos utilizados nas reuniões teóricas

\begin{tabular}{|c|l|c|}
\hline & \multicolumn{1}{|c|}{ Textos } & Supervisoras \\
\hline 01 & $\begin{array}{l}\text { PIMENTA, Selma Garrido; LIMA, Maria Socorro Lucena. Estágio } \\
\text { e docência: diferentes concepções. Em: Poíesis, v. 3, n. 3/4, p. 5-24, } \\
\text { 2005/2006. }\end{array}$ & S1; S2; S3 \\
\hline 02 & $\begin{array}{l}\text { MARTINS, Maria do Carmo. E se o outro é o professor? Reflexões } \\
\text { acerca do currículo e da história de vida. Em: GALLO, Sílvio; SOUZA, } \\
\text { Regina Maria de. Em: Educação do preconceito: ensaios sobre poder } \\
\text { e resistência. Campinas: Editora Alínea, 2004, p. 103-118. }\end{array}$ & S2 \\
\hline 03 & $\begin{array}{l}\text { MILLER, Stela; ARENA, Dagoberto Buim. A constituição dos signifi- } \\
\text { cados e dos sentidos no desenvolvimento das atividades de estudo. Em: } \\
\text { Ensino Em Re-Vista, v. 18, n. 2, p. 341-353, jul./dez. 2011. }\end{array}$ & S1 \\
\hline 04 & $\begin{array}{l}\text { GUERRA, Miriam Darlete Seade. Reflexões sobre um processo vi- } \\
\text { vido no estágio supervisionado: dos limites às possibilidades. 2005. } \\
\text { Disponível em: www.anped.org.br/sites/default/files/gt_08_11.pdf. } \\
\text { Acesso em: 14 jul. 2016. }\end{array}$ & S2 \\
\hline 05 & $\begin{array}{l}\text { OLIVEIRA, Lúcia Colombaretti de. As regências de futuras profes- } \\
\text { soras das séries iniciais: as primeiras experiências com a atividade de } \\
\text { ensinar. Em: Fundamentos em Administração, Letras e Pedagogia, } \\
\text { v. 1, n. 1, p. 27-30, 2005. }\end{array}$ & S3 \\
\hline 06 & $\begin{array}{l}\text { ARAÚJO, Cristina Nalon de; NASCIMENTO, Mari Clair Moro. For- } \\
\text { mação inicial e estágio na pedagogia: vivências e reflexões. Em: Revis- } \\
\text { ta Eletrônica Pró-Docência/UEL. Edição n. 4, v. 1, jul-dez. 2013. }\end{array}$ & S1 \\
\hline
\end{tabular}

Fonte: a própria autora (2016)

Além das reflexões acerca dos conteúdos dos textos, as supervisoras orientaram os estagiários sobre como deveriam se portar na escola e forneceram outras informações necessárias ao momento, havendo também uma breve apresentação da escola onde o estágio seria efetivado. A todo o tempo, elas enfatizaram a importância de os estagiários atentarem para a efetivação da ação docente embasada no exercício da práxis, sendo essencial identificar a teoria que tem embasado a atuação do professor regente " [...] porque toda prática docente está embasada em uma teoria. Para isso, é certo que vocês terão que rememorar o que foi estudado ao longo do curso." (S1). Tal apontamento indica que a interpretação do cotidiano da escola ocorra ancorada nos fundamentos teóricos que os estagiários já estudaram nas demais disciplinas do curso, o que os auxilia na compreensão de que no estágio 
é preciso relacionar teoria e prática. Acerca das orientações das supervisoras (S1; S2; S3) para que os estagiários atentassem para o dia a dia da escola, S1 diz: "Ao estarem em sala de aula, vocês precisam auxiliar a professora, mas também entender o que é essa escola, sobretudo as relações que nela se estabelecem e o mais importante, tentar perceber o que é preciso fazer para a criança aprender.".

Além de tal aspecto, foi enfatizada, também, a importância da intencionalidade na prática docente e a supervisora S1 chama a atenção dos estagiários para tal aspecto no momento de suas intervenções (S1). Já S2 ressalta a relevância de eles se valerem do princípio da alteridade, devido ao estranhamento que pode acontecer na escola, entre quem já está no ambiente e quem está chegando e, ainda, S1 e S3 falam da necessidade do respeito com os sujeitos que lá estão, especialmente, pela professora regente. As supervisoras orientaram, também, para que os estagiários estivessem atentos às características das crianças dos Anos Iniciais do Ensino Fundamental " [...] porque é essencial o professor saber com quem irá atuar." (S2), já que "[...] as crianças dos anos iniciais são diferentes da educação infantil." (S1) e “[...] o professor precisa conhecer as experiências dos seus alunos.” (S3). Assim, as supervisoras chamaram os futuros professores a conhecerem as características dos alunos com os quais atuarão, quando estiverem no exercício da profissão, uma atitude essencial que deve compor a identidade do professor, segundo Sacristán (2005), a busca por conhecer quem é o seu aluno.

Elas destacaram a relevância de os estagiários conhecerem a Proposta Pedagógica das escolas, "[...] porque permite perceber se ela subsidia o planejamento dos professores." (S2), ou seja, "[...] se a prática na sala de aula acontece conforme consta no documento." (S1). A análise deste documento pelos estagiários propicia subsídios para a compreensão de como cada sujeito interpreta e materializa, no dia a dia, o que está indicado no documento da escola, pois, de acordo com Certeau (1998), cada sujeito emprega de um modo diferente os produtos que lhes são indicados. Assim, os estagiários têm orientações para compreenderem o cotidiano da escola, mas com respeito aos sujeitos que lá estão. Nesta perspectiva, S2 faz apontamentos sobre o tempo em que os estagiários estarão na sala de aula, porque "[...] não nos cabe julgar a prática da professora, porque ela tem motivos para efetivá-la de tal forma e é preciso considerar o contexto histórico em que ela teve sua formação”. Dessa forma, a supervisora deixa claro que estágio não é para julgar as ações da professora, mas para pensar sobre como o estagiário agiria diante de determinadas situações.

Nas reuniões, as supervisoras também orientaram sobre a elaboração do diário de campo, pois, nele, deveria constar o que fora observado no dia a dia da escola, sempre com análises fundamentadas teoricamente, o que já ajudaria na elaboração da síntese reflexiva, uma produção a ser realizada ao final do estágio, que seria orientada posteriormente (S1; S2; S3). Conforme disse a supervisora S2:

O diário de campo auxilia a olhar com mais clareza para o que acontece na sala de aula, mas a partir de uma perspectiva teórica. Então é preciso pesquisar também sobre como os estudiosos veem o que está acontecendo na escola. Claro que não daremos conta de tudo, mas vamos direcionar o nosso olhar, principalmente para as questões pedagógicas.

Sobre o diário de campo, Costa e Guindani (2012) afirmam que este recurso oportu- 
niza a retomada de uma situação e o planejamento de novas ações, podendo estabelecer melhorias na prática docente, principalmente, se ela está embasada na pedagogia transmissiva, aquela em que o professor verbaliza os conteúdos a serem memorizados pelos alunos. Destaca-se, portanto, a importância de haver uma prática participativa, aquela em que a construção do conhecimento ocorre na interação entre os sujeitos (OLIVEIRA-FORMOSINHO, 2007a, 2007b). Nela se

[...] realiza uma dialogia constante entre a intencionalidade conhecida para o
acto educativo e a sua prossecução no contexto com os actores, porque estes
são pensados como activos, competentes e com direito a co-definir o itinerário
do projecto de apropriação da cultura a que chamamos educação. (OLIVEIRA-
-FORMOSINHO, 2007a, p. 19).

No que se refere à elaboração da síntese reflexiva, Caimi (2008, p. 150) afirma ser um momento relevante por ser "[...] um instrumento de reflexão que possibilita ampliar a capacidade de ver e de pensar a própria ação docente [...]". Para a sua elaboração os estagiários receberam, via e-mail, a estrutura da produção, sendo esta elaboração individual, devendo ser encaminhada à supervisora que lê e dá os retornos necessários a cada estagiário.

Acerca do planejamento que se efetivaria nos planos de aula, as supervisoras (S1; S2; S3) orientaram que, após as observações participantes, as duplas de estagiários deveriam escolher a turma em que realizariam as intervenções e solicitar à professora regente os conteúdos a serem desenvolvidos. Sobre isso, S1 orientou: "[...] é muito importante tentarmos elaborar planos em que as crianças estejam mais ativas. Os planos serão enviados antecipadamente a mim para correção e só serão aplicados quando estiverem 'redondinhos.".

Nota-se que os planos de aula foram cuidadosamente elaborados pelos estagiários e corrigidos pelas supervisoras. Ao ter acesso a alguns planos de aula, já corrigidos pelas supervisoras, foi possível perceber que haviam apontamentos sobre normas da língua portuguesa, intencionalidade nas atividades e estruturação do plano. Nas adequações solicitadas aos estagiários, por meio de perguntas que os levaram à reflexão sobre o que fora planejado, foi possível verificar a possibilidade que eles teriam de revisão da própria prática, uma ação essencial ao professor. Além das orientações nos próprios planos de aula, quando esses eram enviados via e-mail pelos estagiários às supervisoras, quando eles se encontravam, no dia do estágio curricular, na escola, eram realizados também apontamentos a oportunizarem a revisão das atividades e práticas, no instante das intervenções. Acerca dos planos de aula, cabe aqui um apontamento, porque este documento organiza as ações dos professores intencionalmente evitando improvisos, mas não prevê as situações desafiadoras que se impõem no dia a dia da sala de aula, sendo importante a supervisora" [...] verificar como eles [os estagiários] lidam com as situações de singularidade e incerteza que emergem da sala de aula e de que alternativas lançam mão, se não para solucioná-las, ao menos, para compreendê-las e sobreviver a elas" (CAIMI, 2008, p. 226).

Após a elaboração dos primeiros planos de aula iniciaram-se as intervenções e os planos continuaram a ser elaborados, na medida em elas aconteciam. As supervisoras S1 e S3 realizaram as intervenções com a ida dos estagiários uma vez por semana à escola, durante cinco semanas, já S2 realizou as intervenções blocadas, ou seja, em cinco dias consecuti- 
vos. Elas aconteceram individualmente ou em dupla, conforme orientação das supervisoras, sobre isso S3 disse: "[...] vocês estarão em duplas, mas as intervenções serão individuais. O dia em que uma estagiária estiver intervindo, a outra auxilia”. Para o momento das intervenções, S1 informa: "[...] vou tentar conseguir com a escola que as intervenções sejam de quatro horas, para vocês terem mais tempo para o exercício da docência”, o que realmente aconteceu, porque a rotina da sala de aula foi mudada, de modo a proporcionar aos estagiários atuarem na função da docência em um tempo maior.

No momento das intervenções, estavam presentes, além dos estagiários, a supervisora e a professora regente. Foi possível constatar envolvimentos diferentes das professoras regentes, pois na escola de S1 (ESC1-S1), aquela em que a supervisora conseguiu ajustes para que as intervenções dos estagiários fossem de quatro horas, as professoras em nada auxiliaram os estagiários, mas, na escola de S2 (ESC2-S2) e de S3 (ESC3-S3), as professoras regentes, além de estarem atentas aos conteúdos e atividades desenvolvidas, auxiliaram os estagiários com intervenções junto às crianças, quando solicitadas ou quando perceberam tal necessidade. Ao final da intervenção de cada dia, as supervisoras atribuíram feedback aos futuros professores, sobre o que foi desenvolvido, propiciando que eles refletissem sobre a própria prática, podendo ser ressignificada para a próxima intervenção, pois, conforme indica S1, "[...] é importante perceber se a criança está compreendendo o que está sendo estudado” e assim, as intervenções ocorreram com o acompanhamento in loco pelas supervisoras.

Ao término da carga horária a ser cumprida na escola, houve o seminário de estágio que consiste na participação de todos os estagiários, acompanhados de seus supervisores de campo, para apresentarem “[...] uma breve caracterização do campo de estágio, relatar as atividades e observações desenvolvidas, apresentar a proposta de intervenção, pontuar as dificuldades e as contribuições do estágio para a formação inicial" (UNIVERSIDADE ESTADUAL, 2015, p. 20). Para isso, em seu horário de estudo, os estagiários fizeram explanações sobre atividades e vivências no estágio curricular. Em cada sala, havia dois grupos de estagiários de escolas diferentes. Posteriormente, foram realizados apontamentos sobre os limites e possibilidades do estágio curricular vivenciado. Nos quadros 2 e 3, tais aspectos estão apresentados conforme o reconhecido por cada grupo de supervisoras e seus estagiários:

$\mathrm{Na}$ forma como o seminário de estágio foi sistematizado, possibilitou rememorar o que fora vivenciado no cotidiano da escola, conhecer o que também foi experienciado por um outro grupo de estagiários e, ainda, repensar sobre aspectos facilitadores e dificultadores deste estágio. Nota-se, portanto, que a configuração deste estágio curricular, na instituição pesquisada, deu-se para atenção ao cotidiano escolar, ampliação de conhecimentos referentes ao exercício da docência e, ainda, para saber de seus limites e possibilidades, tendo em vista fazer adequações para os próximos estágios, a partir do que fora posicionado pelos alunos, informação esta que foi repassada pelas supervisoras aos seus estagiários para que pensassem a respeito dos pontos negativos e positivos do estágio nos Anos Iniciais do Ensino Fundamental.

\section{A PERCEPÇÃo DOS SUJEITOS ENVOLVIDOS NO ESTÁGIO CURRICULAR}


Quadro 2 - Limites do estágio curricular apontados pelos estagiários

\begin{tabular}{|c|c|}
\hline $\begin{array}{c}\text { S1 } \\
\text { (ESC1- S1) }\end{array}$ & $\begin{array}{l}\text { (1) Falta de afinidade com os métodos pedagógicos partilhados na escola. } \\
\text { (2) Concepção de criança expressa pela escola. } \\
\text { (3) Indicação das professoras para utilização do livro didático nas ativida- } \\
\text { des de intervenção. } \\
\text { (4) Insegurança diante da inexperiência na docência. }\end{array}$ \\
\hline $\begin{array}{c}\text { S2 } \\
(\mathrm{ESC2}-\mathrm{S2}) \\
\end{array}$ & $\begin{array}{l}\text { (1) Muitas interrupções nas intervenções. } \\
\text { (2) Refazer o plano de aula. }\end{array}$ \\
\hline $\begin{array}{c}\text { S3 } \\
\text { (ESC3-S3) }\end{array}$ & $\begin{array}{l}\text { (1) Greve. } \\
\text { (2) Planejar as atividades das intervenções. }\end{array}$ \\
\hline
\end{tabular}

Fonte: a própria autora (2016).

Quadro 3 - Possibilidades do estágio curricular apontadas pelos estagiários

\begin{tabular}{|c|l|}
\hline $\begin{array}{c}\text { S1; S3 } \\
\text { (ESC1-S1; ES- } \\
\text { C3-S3) }\end{array}$ & (1) Decidir sobre querer, ou não, ser professor dos Anos Iniciais do Ensino \\
\hline S2 & $\begin{array}{l}\text { (1) Auxílio das supervisoras e das professoras regentes no instante das inter- } \\
\text { venções. }\end{array}$ \\
(ESC2-S2) & \\
\hline
\end{tabular}

Fonte: a própria autora (2016).

Esta seção apresenta a sistematização dos dados da pesquisa, obtidos por meio dos instrumentos de coleta, questionários, aplicados junto aos supervisores, estagiários, diretoras, pedagogas, professoras e alunas egressas do curso de Pedagogia, entrelaçados com as observações, realizadas ao longo das reuniões teóricas, no campo e no seminário de estágio, e a entrevista, com a coordenadora do estágio. Assim, serão apresentadas considerações que dão voz às pessoas que estiveram no processo do estágio curricular, bem como aos sujeitos que já passaram por este momento e atuam no exercício da docência, neste caso, as alunas egressas.

Os apontamentos evidenciados visam atender o objetivo do estudo de "mapear as implicações do estágio curricular na formação e na atuação para a docência". Foram identificadas, segundo a visão dos participantes, como ações que interferiram na formação docente ou no dia a dia das escolas onde o estágio curricular se efetivou: (1) o momento das reuniões teóricas, (2) o acompanhamento do estágio in loco pelas supervisoras, (3) a parceria das supervisoras no instante da elaboração dos planos de aula, (4) a ajuda dos estagiários no dia a dia da sala de aula às professoras regentes e (5) os feedbacks atribuídos pelas supervisoras 
aos estagiários.

As reuniões teóricas foram reconhecidas como um momento importante porque, nelas, houve reflexão sobre as finalidades do estágio, a relevância de conhecerem como se organiza o cotidiano da escola, a atuação do professor para a promoção da aprendizagem dos estudantes, chamando os estagiários a pensar sobre as concepções e práticas adequadas à escola contemporânea e, ainda, acerca de como o estágio curricular seria efetivado. Conforme anuncia a supervisora S2, “Os momentos dos estudos teóricos propiciam diálogo sobre a experiência do docente, do aluno e o proposto teoricamente". O estagiário E1-3 diz que elas foram " [...] importantes no sentido de prover uma preparação adequada para a atividade de estágio, realizando-o de forma organizada e intencional no instante das reuniões teóricas". Alunas egressas também expressaram a importância desta etapa do estágio porque as reflexões no instante das reuniões teóricas favoreceram a preparação de suas aulas, já que, nelas, se falava muito da atenção para as especificidades dos alunos e da relevância de estarem ativos no processo de ensinar e de aprender, sendo viável para isso a prática embasada na pedagogia participativa, que se dá na interação com o outro, uma concepção de ensino que considera "[...] imprescindível possibilitar às crianças experiências que possam ser exploradas por um corpo que sente e pensa desde o nascimento" (CARVALHO; FOCHI, 2017, p. 38).

Observar as reuniões teóricas favoreceu perceber que as supervisoras dão voz aos estagiários, já que elas os escutaram e buscaram sanar suas dúvidas e angústias, preparando-os para a entrada e permanência na escola, de forma a respeitarem o espaço que já estaria organizado, valendo-se do princípio da alteridade.

Outra ação reconhecida como aquela que teve interferências no estágio consiste no acompanhamento do estágio in loco pelas supervisoras. A supervisora S1 afirma que procura atuar para que o estagiário possa "[...] o repensar sobre as suas próprias concepções, no que se refere a como se pode efetivar o ato de ensinar de modo que o aluno esteja mais ativo". S3 diz que

[...] o fato dos meus alunos terem a sua supervisora toda semana na escola cria a possibilidade de eles conversarem comigo e sei que isso traz segurança para os estagiários. Eles sabem que não estão sozinhos no processo e nem estão "jogados" na escola para cumprir apenas a carga horária. Neste momento de encontro semanal comigo, eles relatam algumas dificuldades, falam de alguma situação marcante e também pedem conselhos de como devem agir. Acompanhar as intervenções pedagógicas dos alunos em sala de aula: a correção dos planos de aula ou dos projetos de intervenção é um elemento importante no processo de estágio, mas acompanhar o momento em que este plano é colocado em prática também.

Sobre isso, o estagiário E9-S3 disse: "Minha supervisora de estágio foi muito atenciosa, e estava sempre à disposição para ajudar. Orientou muito bem e foi minha base para tudo no estágio." (E9-S3). Também fizeram apontamentos dobre o acompanhamento sistemático pelas supervisoras outros estagiários, alunas egressas e sujeitos da escola, conforme consta abaixo: 
tação quanto à elaboração dos planejamentos, na aplicação destes, nas nossas frustrações após algumas intervenções e no nosso êxito. Durante as reuniões, com o estudo de textos, nos momentos de dialogicidade, entre inúmeras outras questões. (E4-S1).

Com o acompanhamento constante da supervisora, a prática de estágio teve uma visão ampla sobre os aspectos dos anos iniciais do ensino fundamental, ofertando preparação para enfrentar as dificuldades que serão encontradas futuramente, informações da realidade escolar, instigando curiosidade, criatividade, autonomia, valorizando e respeitando a opinião de cada um no âmbito escolar. (E6-S2).

Quando se fala em estágio curricular, é importante ressaltar a importância do papel do supervisor, pois é ele quem direciona a atuação do estagiário e faz as intervenções necessárias para que o estágio tenha um objetivo e esse seja alcançado. [...] eu aprendi muito a partir das intervenções da minha supervisora. Conhecimentos que eu levo para minha sala de aula. (AE-2).

A atuação de bons profissionais que as orientam [as estagiárias] tornou o trabalho das estagiárias produtivo, uma vez que as mesmas realizaram trabalhos diferenciados com os alunos. [...] A presença das supervisoras nas intervenções eu notei ser muito importante, pois possiveis falhas foram sanadas para uma próxima ocasião e obviamente sua ausência é naturalmente sentida neste mesmo aspecto. (PR2-S3).

Ainda sobre a atuação das supervisoras, destaca-se o auxílio que elas deram aos estagiários na elaboração dos planos de aula efetivados nas intervenções, por favorecer a compreensão sobre a relevância da intencionalidade e do exercício das práxis, ao planejarem as atividades a serem realizadas junto aos alunos. A supervisora S1 revela ser importante o "Acompanhamento na elaboração dos planos de aula e das intervenções: é o momento em que se pode promover continuamente a reflexão sobre o planejamento intencional, a atuação direta com as crianças e a experiência inicial da docência. O estagiário E7-S1 afirma que

A maioria dos(as) estagiários(as) ainda não possui ampla experiência na elaboração dos planejamentos, desse modo, muitas indagações surgem. Dentre elas pode-se destacar: como abordar determinado conteúdo? Qual atividade é mais adequada? Quais os objetivos mais apropriados? Etc. Nesse enfoque, a orientação do supervisor é essencial.

Alunas egressas também expressam a importância da supervisora no momento da elaboração dos planos de aula:

Contribuições para o aprimoramento do plano de aula: considerando a inexperiência quanto à docência, foram importantes as ideias e referências recebidas pela supervisora de estágio. Puderam dar mais embasamento teórico para as intervenções. (AE5).

Elaboração do plano de intervenção, pois este é o momento de estudo, pesquisa, con- 
fronto entre a realidade observada (mesmo que num curto prazo), a teoria aprendida e o fazer docente. Execução do plano de intervenção, pois é o primeiro momento em que o estagiário tem a possibilidade de vivenciar a prática da docência. (AE7).

Todavia, cabe, neste momento, atentar para os apontamentos da escola ESC2-S2, pois, segundo a diretora D2- S2, “[...] as estagiárias trazem o planejamento em cima da hora e às vezes nem o apresentam. Isso impede que a regente possa colaborar com sugestões que dariam mais certo". Nota-se, portanto, uma insatisfação da escola pela exclusão da participação das professoras regentes na elaboração dos planos de aula, sendo viável pensar sobre o papel que elas desempenham no estágio curricular e, ainda, acerca da parceria entre a universidade e a escola. Sobre isso, o estudo de Cyrino (2016) destaca a importância do trabalho colaborativo ou compartilhado entre as instituições de ensino superior e as escolas, de forma que os envolvidos no processo ofereçam ao futuro professor um contexto de aprendizagem, em que o acompanhamento esteja a serviço da reflexão para a melhoria da ação docente.

De acordo com França (2009), para isso existir, é preciso superar a concessão da sala de aula para ações do estagiário pela reflexão sobre as necessidades da escola. Mira e Romanowski (2012) afirmam que o estágio precisa contribuir com as demandas de cada escola, o que nos chama a rever o lugar que os sujeitos que lá estão ocupam no processo do estágio. Segundo Zeichner (2000), se o estágio for concretizado a partir de uma parceria pode oportunizar a melhoria dos saberes de todos os envolvidos, sendo necessário estreitar a relação entre professores em formação, professores mais experientes e os demais profissionais que lá estão. Para isso, é preciso superar a hierarquia de saberes, conforme apontam Cyrino e Neto (2015, p. 410), porque "[...] na nossa sociedade, o conhecimento originado na universidade apresenta um status, um nível de importância maior do que os conhecimentos produzidos na prática escolar [...]”.

A relevância do estágio acontecer a partir da parceria entre a escola e a universidade também é destaque no estudo de Rabelo (2019), por interferir na formação inicial e continuada para a docência. "A parceria universidade e escola tem sido exaltada porque vários estudos constatam a distância entre a formação inicial e a realidade encontrada nas escolas e a lacuna entre teoria/prática, formação/trabalho." (p. 46). Afirmação também encontrada na pesquisa de Rocha, Bosco e Eiterer ao indicarem "[...] que o diálogo com as escolas de Educação Básica é inexpressivo ou mesmo, inexistente." (p. 48804).

Foi apontado também que a presença dos estagiários na sala de aula possui implicações porque muda a rotina, diz a professora PR2-S3: "Qualquer presença estranha ao meio altera a dinâmica da sala, o que não quer dizer que seja necessariamente ruim; em muitos momentos a presença de estagiários pode ser enriquecedora e produtiva." (PR2-S3), "Contribuindo efetivamente com a rotina escolar dos alunos, através de dinâmicas e atividades especificas que, juntamente com o professor regente, contribuem para o desenvolvimento dos alunos.” (PR1-S3). Segundo a professora PR2-S3, “[...] os estágios contribuem para o dinamismo da prática em sala de aula, pois há propostas de intervenções com atividades variadas. Outro ponto é a colaboração das estagiárias com a professora em sala de aula". Assim, a ajuda dos estagiários no dia a dia da sala de aula às professoras regentes 
também foi apontada como uma ação que tem implicações no estágio, porque possibilitou a elas maior tempo de dedicação às crianças, especialmente, àquelas que precisam de atenção em função de suas dificuldades

E ainda, os feedbacks atribuídos pelas supervisoras aos estagiários, sendo esta mais uma ação que teve implicações no estágio curricular, principalmente, na formação dos futuros professores porque, de acordo com a aluna egressa AE5: "Os feedbacks recebidos permitiram o aprimoramento das ações que ocorreram posteriormente, objetivando sempre o melhor, para alcançarmos um ensino cujo objetivo principal era o aprendizado das crianças". A aluna egressa AE6 disse que "Sempre houve uma devolutiva de como foi a regência. Essa ação considero importantíssima, pois é só através dela que podemos perceber onde e como melhorar nossa atuação em sala". A supervisora S1afirma que, no momento do feedback, objetiva que estagiários reflitam sobre a própria prática, logo que ela acontece porque "[...] é importante perceber se a criança está compreendendo o que está sendo estudado".

Então, o feedback ocorreu, no estágio curricular, mediante a devolutiva e apontamentos da supervisora sobre as ações empreendidas pelo estagiário, sempre visando a construção da identidade docente que oportunize melhorias no conhecimento das crianças. No entanto, cabe destacar o que aponta o estudo de Cyrino (2016), acerca do feedback aos estagiários, pois sua pesquisa apresenta uma proposta de estágio colaborativo ou compartilhado entre os sujeitos envolvidos no processo. Nesta proposta, o feedback se deu também por parte das professoras regentes aos futuros professores, aspecto que foi reconhecido pelos estagiários como positivo. Então, a partir de um bom acolhimento das professoras aos estagiários, foram realizados apontamentos sobre: (a) preparo das atividades; (b) como escrever e organizar os textos na lousa; (c) letra adequada a utilizar; (d) modo de conduzir a aula; (e) vocabulário; (e) maneiras de melhorar a estratégia e o conteúdo ministrado; (f) organização dos documentos docentes; (g) alfabetização; (h) objetivos pedagógicos e (i) tempo das atividades, entre outros saberes necessários ao exercício da docência.

Todavia, após apresentação das ações que, segundo os sujeitos envolvidos no estágio curricular em estudo neste texto, tiveram implicações na formação docente ou no dia a dia da escola, cabe uma reflexão a respeito da alteração realizada no cotidiano da escola ESC1-S1, aquela em que a supervisora solicitou tal aspecto para que os estagiários realizassem suas intervenções no período de quatro horas, pois se o estágio curricular tem como um de seus objetivos conhecer o cotidiano da escola, seria viável a sua alteração? Frente ao fato, convém também pensar se a falta de envolvimento das professoras regentes junto aos estagiários, no instante de suas intervenções, seria consequência deste aspecto, visto que, para estarem nas intervenções, elas abriram mão da hora-atividade.

\section{CONSIDERAÇões FINAIS}

A pesquisa traz dados sobre a configuração de um modelo de estágio curricular em que as etapas são estruturadas com o objetivo de proporcionar a construção da identidade docente, visto ser essa a base para a formação do Pedagogo na universidade em que se deu o estudo. Dos achados aqui enumerados, vale destacar aqueles que chamam a olhar para o 
que ainda precisa ser revisto no estágio curricular, primeiramente, para a relação que tem sido estabelecida entre a escola e a universidade, e, ainda, para a formação do professor que saiba lidar com as demandas da escola contemporânea.

Sobre a relação existente entre a escola e a universidade, nota-se que esta ainda é uma reflexão que necessita ser aprofundada e um relacionamento a ser estreitado, pois tem-se evidência, neste estudo e em outros já mencionados ao longo deste texto, de que os sujeitos da escola não ocupam a mesma posição daqueles que vêm da academia, visto o clamar de uma das escolas pela participação das professoras regentes na elaboração das atividades a serem efetivadas em suas próprias salas de aula. Neste cenário, torna-se importante pensar em um modelo de estágio que, além de voz aos estagiários, dê espaço para aqueles que já se encontram no campo social da atuação docente porque, nesta relação, todas as pessoas envolvidas têm a ganhar, especialmente, as crianças, pois o aprimoramento das ações, principalmente aquelas relativas à docência, pode-se ter em decorrência a ampliação dos conhecimentos dos estudantes, a razão de existir do processo educativo e da instituição escola.

Acerca da formação do professor que saiba lidar com as demandas da escola contemporânea, chama-se à reflexão sobre ter o professor que domine os conteúdos da sua área de conhecimento, mas que ele atenda também ao perfil de aluno deste contexto histórico com compromisso político, ou seja, que ele identifique e compreenda como os conteúdos estão apresentados nos documentos que organizam a educação, com atenção especial para o currículo, tendo em vista identificar a concepção de sujeito a ser formado. Para isso, não basta compreender o cotidiano da escola e saber fazer plano de aula, porque é preciso ter conhecimentos teóricos e práticos para agir diante das situações imprevistas que se apresentam a cada instante. Frente ao exposto, é preciso pensar em um modelo de estágio que se efetive na parceria entre a escola e a universidade e que oportunize ao estagiário, futuro professor, adquirir fundamentos e práticas a possibilitarem a transformação de determinada realidade, principalmente, quando ela conduzir à opressão. Mas, para isso, é preciso ter um professor que faça análises e intervenções no cotidiano da escola em que atua.

\section{REFERÊNCIAS}

ARAÚJO, Osmar Hélio Alves; MARTINS, Elcimar Simão. Estágio curricular supervisionado como práxis: algumas perguntas e possíveis de respostas. Em: Reflexão e Ação. Santa Cruz do Sul, v. 28, n. 1, p. 191-203, jan/abr. 2020. Disponível em: https://online.unisc.br/ seer/index.php/reflex/article/view/12902/pdf. Acesso em: 14 fev. 20221.

AZANHA, José Mário Pires. Comentários sobre a formação de professores em São Paulo. Em: SERBINO, Raquel Volpato et al. Formação de professores. São Paulo: Editora da UNESP, 1998, p. 49-58.

AZANHA, José Mário Pires. Uma reflexão sobre a formação do professor da escola básica. Em: Educação e Pesquisa, São Paulo, v. 30, n. 2, p. 369-378, maio/ago., 2004. Disponível em: http://www.scielo.br/scielo.php?script=sci_arttext\&pid=S1517-97022004000200016. Acesso em: 14 abr. 2016. 
BOGDAN, Robert; BIKLEN, Sari. Investigação qualitativa em educação. Porto Alegre: Porto Editora, 1994.

BOURDIEU, Pierre; PASSERON, Jean-Claude. A Reprodução. Tradução de: Reynaldo Bairão. Rio de Janeiro: Francisco Alves, 1982.

BRUNER, Jerome. A Cultura da Educação. Lisboa: Edições 70, 1996.

CAIMI, Flávia Elisa. Aprendendo a ser professor de história. Passo Fundo: Editora Universidade de Passo Fundo, 2008.

CARVALHO, Rodrigo Saballa de; FOCHI, Paulo Sergio. Pedagogia do cotidiano: reivindicações do currículo para a formação de professores. Em Aberto, Brasília, v. 30, n. 100, p. 23-42, set./dez. 2017. Disponível em: http://www.emaberto.inep.gov.br/ojs3/index.php/ emaberto/article/view/3212/2947. Acesso em: 14 fev. 2021.

CERTEAU, Michel de. A invenção do cotidiano: artes de fazer. v. 1. $3^{\mathrm{a}}$ ed. Petrópolis: Vozes, 1998.

CYRINO, Marina; NETO, Samuel de Souza. O estágio curricular no curso de pedagogia: elementos para um processo formativo. Acta Scientiarum. Education, Maringá, v. 37, n. 4, p. 401-413, Oct.-Dec., 2015. Disponível em: https://www.redalyc.org/ pdf/3033/303343304008.pdf. Acesso em: 14 fev. 2021.

CYRINO, Marina. Do acolhimento ao acompanhamento compartilhado: a construção colaborativa de uma proposta para o estágio curricular no curso de pedagogia. 2016. 345 f. Tese (Doutorado em Educação) - Universidade Estadual Paulista Júlio de Mesquita Filho, Rio Claro, 2016. Disponível em: https://repositorio.unesp.br/bitstream/handle/11449/137997/cyrino_m_dr_rcla.pdf?sequence=3\&isAllowed=y . Acesso em: 12 jul. 2021.

COSTA, Joyce Vieira da.; GUINDANI, Miriam Krenzinger. Didática e pedagogia do diário de campo na formação do assistente social. Em: Revista Virtual Emancipação, Ponta Grossa, v. 12, n. 2, p. 265-278, 2012. Disponível em: http://www.revistas2.uepg.br/index. php/emancipacao/article/view/3404/3294. Acesso em: 02 fev. 2017.

FARIAS, Isabel Maria Sabino. Inovação e mudança: implicações sobre a cultura dos professores. 2002. 260f. Tese (Doutorado em Educação) - Faculdade de Educação, Universidade Federal do Ceará, Fortaleza, 2002.

FRANÇA, Dimair de Souza. Formação do pedagogo: a orientação dos estágios de ensino pelo professor da escola básica. Em: IX Congresso Nacional de Educação - EDUCERE. III Encontro Sul Brasileiro de Psicopedagogia - PUCPR. out. 2009. Disponível em: http:// educere.bruc.com.br/arquivo/pdf2009/3064_1382.pdf. Acesso em: 01 out. 2016.

GIGLIO, Célia Maria B. et al. Residência Pedagógica: diálogo permanente entre a forma- 
ção inicial e a formação contínua de professores e pedagogos. Em: GOMES, Marineide de Oliveira. Estágios na formação de professores: possibilidades formativas entre ensino, pesquisa e extensão. São Paulo: Edições Loyola, 2011, p. 15-46.

GUERRA, Isabel Carvalho. Pesquisa qualitativa e análise de conteúdo: sentidos e formas de uso. Portugal: Princípia Editora, 2008.

KINCHELOE, Joe. L. A formação do professor como compromisso político: mapeando o pós-moderno. Tradução de: Nize Maria Campos Pellanda. Porto Alegre: Artes Médicas, 1997.

LIBÂNEO, José Carlos. A aprendizagem escolar e a formação de professores na perspectiva da psicologia histórico-cultural e da teoria da atividade. Em: Educar, Curitiba, n. 24, p. 113-147, 2004. Disponível em: http://www.scielo.br/pdf/er/n24/n24a06.pdf. Acesso em: 12 out. 2017.

LIMA, Maria do Socorro Lucena; AROEIRA, Kaline Pereira. O estágio curricular em colaboração, a reflexão e o registro reflexivo dos estagiários: um diálogo entre a universidade e a escola. Em: GOMES, Marineide de Oliveira (Org.). Estágios na formação de professores: possibilidades formativas entre ensino, pesquisa e extensão. São Paulo: Loyola, 2011.

LONDRINA. Proposta Político-pedagógica. ESC1. 2015.

LONDRINA. Proposta Político-pedagógica. ESC2. 2016.

LONDRINA. Proposta Político-pedagógica. ESC3. 2017.

LÜDKE, Menga; ANDRÉ, Marli Eliza Dalmazo de. Pesquisa em educação: abordagens qualitativas. São Paulo: EPU, 1986.

MINAYO, Maria Cecília de Souza (Org.). Pesquisa Social: teoria, método e criatividade. $18^{\mathrm{a}}$ ed. Petrópolis: Vozes, 2012.

MIRA, Marilia Marques; ROMANOWSKI, Joana Paulin. A relação universidade-escola no estágio supervisionado do curso de pedagogia: desafios e possibilidades. Em: EntreVer, Florianópolis, v. 2, n. 3, p. 184-199, jul./dez. 2012. Disponível em: https://periodicos.ufsc. br/index.php/EntreVer/article/view/34249. Acesso em: 01 out. 2017.

MORGADO, Tania Maria Cristina. Prática de Ensino Supervisionada em Educação Pré-Escolar. 2012. 88f. Dissertação (Mestrado em Educação) - Escola Superior de Educação, Instituto Politécnico de Bragança, Bragança, 2012. Disponível em: https://bibliotecadigital.ipb.pt/bitstream/10198/7685/1/Relat\%C3\%B3rio\%20da\%20Pr\%C3\%A1tica $\% 20 \mathrm{de} \% 20$ Ensino $\% 20$ Supervisionada $\% 20 \mathrm{em} \% 20$ Educa $\% \mathrm{C} 3 \% \mathrm{~A} 7 \% \mathrm{C} 3 \% \mathrm{~A} 3 \mathrm{o} \% 20$ 
Pr\%C3\%A9-Escolar.pdf. Acesso em: 13 dez. 2014.

OLIVEIRA-FORMOSINHO, Júlia. Pedagogia(s) da infância: dialogando com o passado, construindo o futuro. Porto Alegre: Artmed, 2007a.

OLIVEIRA-FORMOSINHO, Júlia. A utilização da herança histórica na reconstrução de uma práxis de participação. Em: OLIVEIRA-FORMOSINHO, Júlia. Modelos curriculares para a educação de infância: construindo uma práxis de reflexão. Porto: Porto Editora, 2007b, p. 13-42.

PICONEZ, Stela C. Bertholo (Coord.). A prática de ensino e o estágio supervisionado. Campinas: Papirus, 1991, p. 15-38.

PIMENTA, Selma Garrido. Prefácio. Em: GOMES, Marineide de Oliveira. Estágios na formação de professores: possibilidades formativas entre ensino, pesquisa e extensão. São Paulo: Edições Loyola, 2011, p. 9-14.

RABELO, Amanda Oliveira. O estágio curricular obrigatório e a formação do professor dos Anos Iniciais do Ensino Fundamental no Brasil. Em: RELVA. Juara, v. 6, n. 2, p. 39-59, jul./dez. 2019. Disponível em: https://periodicos.unemat.br/index.php/relva/article/ view/4225/3381. Acesso em: 12 jul. 2021.

ROCHA. Gladys; BOSCO, Cláudia Starling, EITERER. Reflexões sobre saberes construídos no estágio curricular a partir de percepções discentes e docentes. Em: Braz. J. of Develop., Curitiba, v. 6, n. 7, p. 48798-48813, jul. 2020. Disponível em: https://www.brazilianjournals.com/index.php/BRJD/article/view/13550/11353. Acesso em: 12 jul. 2021.

SACRISTÁN, Gimeno. O aluno como invenção. Porto Alegre: Artmed, 2005.

SILVA, Haíla Ivanilda Silva, GASPAR, Mônica Gaspar. Estágio supervisionado: a relação teoria e prática reflexiva na formação de professores do curso de Licenciatura em Pedagogia. Em: Rev. bras. Estud. pedagog., Brasília, v. 99, n. 251, p. 205-221, jan./abr. 2018. Disponível em: https://www.scielo.br/pdf/rbeped/v99n251/2176-6681-rbeped-99-251-205. pdf. Acesso em: 14. Fev. 2021.

UNIVERSIDADE ESTADUAL. Projeto político-pedagógico. 2005. Disponível em: http://www.uel.br/ceca/pedagogia/pages/arquivos/PPP2005.pdf. Acesso em: 30 jul. 2013.

UNIVERSIDADE ESTADUAL. Projeto político-pedagógico. 2007. Disponível em: http://www.uel.br/ceca/pedagogia/pages/arquivos/PPP2007.pdf Acesso em: 30 jul. 2013.

UNIVERSIDADE ESTADUAL. Resolução CEPE No 0166/2008. 2008. Disponível em: http://www.uel.br/prograd/docs_prograd/resolucoes/resolucao_166_08.pdf. Acesso em: 14 ago. 2013.

UNIVERSIDADE ESTADUAL. Projeto político-pedagógico. 2010. Disponível em: 
http://www.uel.br/ceca/pedagogia/pages/arquivos/PPP\%20-\%202010.pdf. Acesso em: 30 jul. 2013.

UNIVERSIDADE ESTADUAL. Diretrizes do Estágio Curricular Obrigatório nos Anos Iniciais do Ensino Fundamental do Curso de Pedagogia. 2015.

VÁZQUEZ, Adolfo S. Filosofia da práxis. Rio de Janeiro: Paz e Terra, 1968.

ZEICHNER, Kenneth M. Formação de professores: contato direto com a realidade da escola. Em: Presença Pedagógica, Belo Horizonte, v. 6, n. 34, p. 5-15, jul./ago. 2000. Disponível em: http://pt.slideshare.net/viviprof/k-zeichner-entrevista. Acesso em: 26 mai. 2016.

\section{DADOS DA AUTORAS}

\section{Mari Clair Moro Nascimento}

Doutora em Educação pela Universidade Estadual Paulista Júlio de Mesquita Filho (UNESP), Campus de Marília/SP. Mestre em Educação pela Universidade Estadual de Londrina (UEL).mariclairmoro@hotmail.com

\section{RaQuel Lazzari Leite Barbosa}

Professora adjunta na Faculdade de Ciências e Letras, UNESP, Assis/SP e Professora Orientadora do Programa de Pós-Graduação em Educação da Faculdade de Filosofia e Ciências, UNESP, Marília/SP. raqueleite@uol.com.br

Submetido em: 28-02-2021

Aprovado em: 16-07-2021 